\title{
Tie-Braces Design Optimization of Breasting Dolphin Structure at Petrochina Marine Terminal
}

\author{
Rudi W Prastianto a," , Dyah A Puspitorini ${ }^{\mathrm{b}}$ and Yoyok S Hadiwidodo ${ }^{\mathrm{a}}$ \\ a) Associate Professor, Department of Ocean Engineering, Institut Teknologi Sepuluh Nopember, Kampus ITS - Sukolilo, Surabaya 60111, \\ Indonesia \\ b) Student, Department of Ocean Engineering, Institut Teknologi Sepuluh Nopember, Kampus ITS - Sukolilo, Surabaya 60111, Indonesia \\ *Corresponding author: rudiwp@oe.its.ac.id
}

\begin{abstract}
This paper discusses about optimization design of breasting dolphin's structural strengthening with additional tie-braces. The breasting dolphin structure has failed because of the increased load on the export activity of tanker. A strengthening project has been carried out in 2014, but the result is considered overdesign and is not optimal. Therefore an optimization design of breasting dolphin structure is carried out as described herein, by looking for the optimum configuration, outside diameter, and wall thickness. The objective function is to determine the minimum weight of the structure. The independent variables are the outside diameter and wall thickness. The constraints are joint deflection check, member stress check, and joint punching shear stress check. There two type analyses performed. Firstly, in-place analysis of several structures with various tie-braces dimensions. The calculation of the initial tie-braces dimension was performed using parameter's design according to API RP 2A WSD. Secondly is optimization analysis of output data from the in-place evaluation to determine optimum outside diameter and wall thickness of tie-braces, also the weight of the structure. After optimization analysis conducted it is found optimum structural weight be 261 tons, which is some 3 tons lighter than the previous one of 264 tons.
\end{abstract}

Keywords: optimization, breasting dolphin, tie-braces, independent variable, constraint

\section{INTRODUCTION}

Petrochina Marine Terminal is an LPG and Oil/Condensate Terminal located at Berhala Straits, offshore Jambi, Indonesia, first installed in 2004 and owned by Petrochina International Jabung Ltd. The Terminal capable for simultaneously receiving and discharging operations. Crude oil and condensate are stored and offloaded in a controlled, pressurized, environment and metered by tank ullage measurement in the terminal. The terminal consists of 7 Mooring Dolphins and 3 Breasting Dolphins [1].

Dolphin structure is a fixed offshore structures constructed to withstand the horizontal forces caused by the vessel impacts and to control the transverse movement of berthing vessels due to wind, currents and waves. Dolphin structures can be divided into two type, the first is dolphin holder (breasting dolphin) and the second is mooring dolphin. Breasting dolphin has a fender that is used to withstand the impact forces of the vessel and keep the vessel from pressing against the pier structure. Whilst mooring dolphin has a mooring line that is used to resist the pulling load of the vessel so it stays in the docked position [2].

Over the years, oil/condensate production has increased considerably. The terminal have to cope with the increasing production and exporting cargoes activity from onshore fields. Production for cargoes will also be gradually increased to meet National Target Production of Indonesia. Larger production means increase in the load, which may lead to the failure of the breasting dolphin structure. In this regards structure in-place analyses for the related breasting dolphins need to be performed to cope with the new berthing loads due to the increased export activities.

From the in-place analysis, it is shown that several piles above the mud line do not satisfy the capacity requirement since the UC's are more than allowable limit. Therefore, breasting dolphin structural strengthening project were carried out by Petrochina. Breasting dolphin structural strengthening design was done by adding horizontal and vertical tie-braces on the jacket legs structure. Most of the $\mathrm{X}$-braces configuration are selected to horizontal and diagonal tie-braces.

After analyzing the structural design of breasting dolphin with additional tie-braces, it was found that all the member structure have combined stress within allowance (maximum UC is 0.46 on operating conditions), which means that the structure is safe to operate. However, in designing the structure, optimization analysis necessary to be done in view of high opportunity to attain an effectivecost of fabrication. At the design stage activities may cover determination of configuration, size/dimensions and type of structural material [3]. 
This paper is prepared to present the optimization analysis conducted on the breasting dolphin structure strengthening design at Petrochina Marine Terminal.

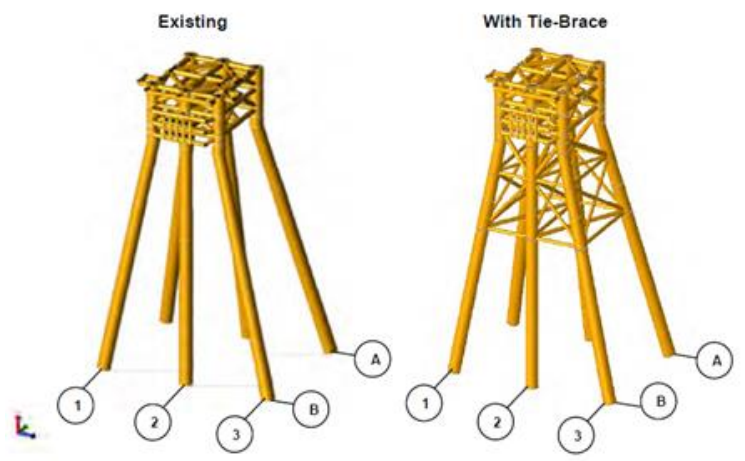

Figure 1. Comparison existing - modification breasting dolphin with additional tie-braces

\section{MATERIALS AND METHODS}

\subsection{Data Collection}

The object of this case (study) is breasting dolphin structure owned by PT Petrochina International Jabung Ltd. This structure was installed in the Berhala Strait, offshore Jambi, Indonesia. The data includes the structural data (jacket, topside deck, and appurtenances) and design criteria data (loading and environmental data).

\subsection{Modeling and Validation}

The modeling of Breasting Dolphin structure is commenced by employing a FEM software to derive the output of inplace analysis. This is further to be validated against the existing data from the project report. Validity is achieved when the difference between the results of the analysis in comparison to the existing data is less than $4 \%$. After validation the structure could be processed for the next analysis.

\subsection{Design Variables}

The independent variables were selected in this study, comprising of the outside diameter and wall thickness of tiebraces. The objective function is to minimize the weight of the structure. Constraints selected are joint deflection, member stress, and joint punching shear stress check.

\subsection{Selection Type of Tie-Braces}

Selection type of tie-braces is determined by reviewing the tie-braces combined UC on several structures by varying the joint types ( $\mathrm{K}, \mathrm{V}, \mathrm{N}, \mathrm{V}$ and $\mathrm{X}$, and $\mathrm{X}$ braces). In the evaluation, all dimensions of tie-braces are designed with the same size, so the type of tie-braces are selected by reviewing the structure that has less different combined UC for its tie-brace members.

\subsection{Selection Initial Dimension of Tie-Braces}

Selection initial dimension of tie-braces is based on a tubular design parameters stated in API RP 2A WSD.

\subsection{Modeling and In-place Analysis}

Modeling some of breasting dolphin structures with a variety of dimensions and in-place analysis will be done to determine maximum joint deflection check, maximum member stress check (UC), joint punching shear stress check (UC), and total self weight of the structure.

\subsection{Optimum Tie-Braces Dimensional Selection}

The optimum dimensions of tie-braces are determined by making plot a graph of the results (output) of the in-place analysis on several structures. The optimum criteria can be achieved when the dimensions of the tie-braces intersect with constraint, also by looking at the minimum self weight of the structure.

\subsection{Review and Analysis}

Review will be made on the results of the strengthening of the structure of breasting dolphin that has been done by PT Petrochina International Jabung Ltd and compare those with the results of the current study.

\section{RESULTS AND DISCUSSIONS}

\subsection{Breasting Dolphin General Data}

The modeling of the floating structure is established by

- Jacket Leg :

- Total : 6

- Outside Diameter $\quad: 121.9 \mathrm{~cm}$ and 115.57

$$
\mathrm{cm}
$$

- Wall Thickness $\quad: 3.175 \mathrm{~cm}$ and $3.165 \mathrm{~cm}$

- Topside Deck :

- Total :3

- Outside Diameter $\quad: 121.9 \mathrm{~cm}$

- Wall Thickness $\quad: 3.175 \mathrm{~cm}$

- Main Deck El. : : (+) $9.50 \mathrm{~m}$

- Cellar Deck El. : : (+) $7.35 \mathrm{~m}$

- Sub Cellar Deck El. : : (+) $5.20 \mathrm{~m}$

- Appurtenances $\quad: 1$ fender support

Strengthening breasting dolphin project was carried out with the additional tie-braces in 2014 :

(a) Diagonal tie-braces from El. (+) $4.65 \mathrm{~m}$ to El. (+) 0.0 $\mathrm{m}$

(b) Diagonal tie-braces from El. (+) $0.0 \mathrm{~m}$ to El. (-) 6.0 $\mathrm{m}$

(c) Horizontal tie-braces from El. (+) $0.0 \mathrm{~m}$ and El. (-) $6.0 \mathrm{~m}$

Details of the strengthening design on the structure are shown in Fig.2 and Fig.3. 


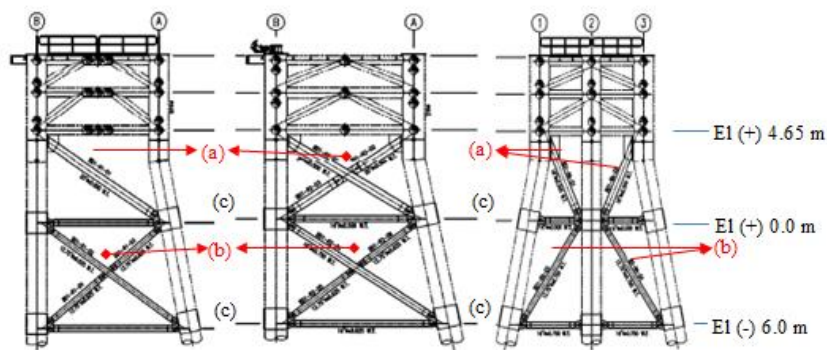

Figure 2. Diagonal tie-braces of breasting dolphin
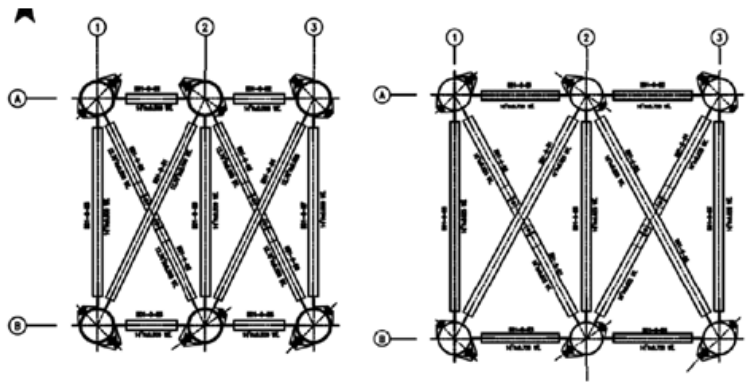

Figure 3. Horizontal Tie-braces at El (+) 0.0 meter (left) and $\mathrm{El}(+) 6.0$ meter (right)

- Design Criteria

The design criteria applied for the breasting dolphin design criteria is shown in Table 1.

Table 1. Load case of breasting dolphin

\begin{tabular}{|c|l|r|}
\hline \multicolumn{2}{|c|}{ Load Case } & Load \\
\hline \multirow{4}{*}{$\begin{array}{c}\text { Dead } \\
\text { Load }\end{array}$} & Self Weight & $263.60 \mathrm{ton}$ \\
\cline { 2 - 3 } & Non Generated Comp & $148.76 \mathrm{kN}$ \\
\cline { 2 - 3 } & Bridge Dead Load X-dir & $73.5 \mathrm{kN}$ \\
\cline { 2 - 3 } & Bridge Dead Load Y-dir & $180 \mathrm{kN}$ \\
\hline \multirow{3}{*}{$\begin{array}{c}\text { Berthing } \\
\text { Tanker }\end{array}$} & Live Load & $7.5 \mathrm{kN}$ \\
\cline { 2 - 3 } & X-direction & $774 \mathrm{kN}$ \\
\hline
\end{tabular}

\subsection{Breasting Dolphin Model Validation}

A three-dimensional finite element computer model for the breasting dolphin has been compiled, as depicted in Fig. 4. Non-modeled members such as handrails, grating, pad eyes, anodes, etc. have been hand coded as non-generated dead loads.

Model validation is conducted to examine the appropriateness and suitability of the structural modeling that has been done in relation to the actual structure. The validation is made on five primary parameters, as presented in Table 2.

Table 2. Results of model validation

\begin{tabular}{|l|c|c|c|}
\hline \multicolumn{1}{|c|}{ Description } & Data & Analysis & Differ \\
\hline Self Weight $(\mathrm{kN})$ & 2586.04 & 2588.03 & $0.07 \%$ \\
\hline Env Load 0 deg $-\mathrm{Fx}(\mathrm{kN})$ & 732.400 & 732.790 & $0.05 \%$ \\
\hline Env Load 45 deg - Fx $(\mathrm{kN})$ & 494.566 & 494.800 & $0.05 \%$ \\
\hline Env Load 90 deg - Fy $(\mathrm{kN})$ & 598.864 & 598.920 & $0.01 \%$ \\
\hline Env Load 135 deg $-\mathrm{Fx}(\mathrm{kN})$ & -494.566 & -494.800 & $0.05 \%$ \\
\hline
\end{tabular}

As all the differences are less than $4.0 \%$, so the breasting dolphin structure model can be used for the next analysis.

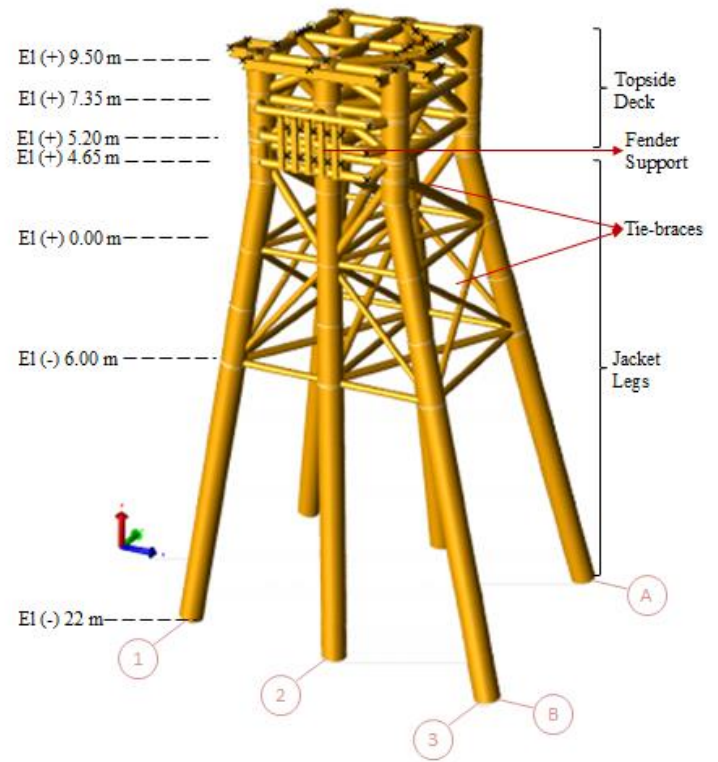

Figure 4. Existing breasting dolphin model

\subsection{Design Variable Checks}

As afore mentioned, the independent variables considered are outside diameter and wall thickness of tie-braces. The objective function is to minimize the weight of the structure. Whilst the constraints selected are joint deflection check, member stress check (maximum UC), and joint punching shear stress check (maximum UC).

Maximum Deflection. The structure is considered safe when the deflection occurred is less than the allowable deflection limit. The allowable deflection limit is calculated by the equation $\mathrm{L} / 200$ where, $\mathrm{L}$ is the length of the member, namely the pile. The allowable deflection limit was $12.5 \mathrm{~cm}$, for the pile length of $25 \mathrm{~m}$.

Because here the optimization analysis is used for minimizing the weight of the structure, which means optimum criteria is reached when the independent variables intersect with the constraint, then the optimum dimensions occurred when the independent variables intersect with the allowable deflection limits.

Maximum UC. The structure is considered safe when the UC occurred is less than the allowable limit. The allowable UC limit is 1.0. Because here the optimization analysis is aimed to minimize the weight of the structure, which means optimum criteria is reached when the independent variables intersect with the constraint, then the optimum dimensions attained when the independent variables intersect with the allowable limits.

\subsection{Selection Type of Tie-Braces}

Selection type of tie-braces is determined by reviewing tiebraces combined UC from in-place analysis on several 
breasting dolphin structures with varying forms of type braces; these are $\mathrm{K}, \mathrm{V}, \mathrm{N}, \mathrm{V}$ and $\mathrm{X}$, and $\mathrm{X}$ braces [4]. The structures modeled and analyzed in FEM software with the outside diameter of tie-braces size of $30 \mathrm{~cm}$ and the wall thickness size of $1.55 \mathrm{~cm}$. Table 3 shows the results of inplace analysis from several breasting dolphin structure.

Table 3. Five maximum combined UCs from breasting structures with several type of tie-braces

\begin{tabular}{|c|c|c|c|c|}
\hline $\begin{array}{c}\text { K- } \\
\text { brace }\end{array}$ & V-brace & N-brace & $\begin{array}{c}\text { V \& X- } \\
\text { brace }\end{array}$ & $\begin{array}{c}\mathbf{X}- \\
\text { brace }\end{array}$ \\
\hline 101.38 & 101.41 & 101.38 & 0.73 & 0.90 \\
\hline 1.40 & 1.48 & 1.40 & 0.62 & 0.87 \\
\hline 0.60 & 0.73 & 0.60 & 0.61 & 0.86 \\
\hline 0.57 & 0.53 & 0.54 & 0.58 & 0.73 \\
\hline 0.45 & 0.53 & 0.44 & 0.57 & 0.50 \\
\hline
\end{tabular}

From the Table 3 the breasting dolphin structure having least combined UCs is the breasting dolphin structure with $\mathrm{V}$ and $\mathrm{X}$ - braces configuration. So this is the one considered as the optimum configuration of tie-braces for the breasting dolphin structure in the Berhala Strait. Further it will serve as a model for determining the optimum dimensions, as exhibited in Figs. 5 and 6.

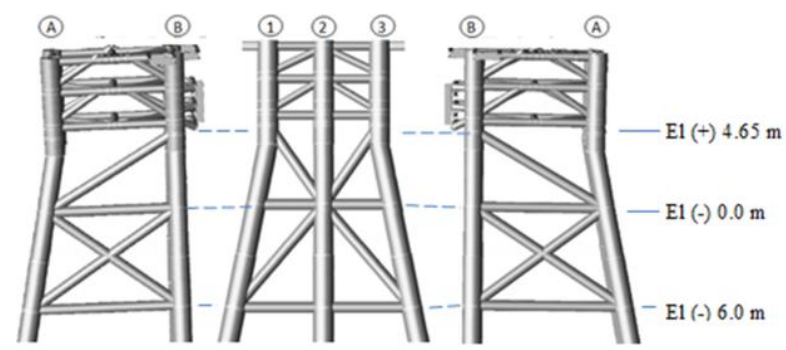

Figure 5. Redesign - diagonal tie-braces of breasting dolphin structure
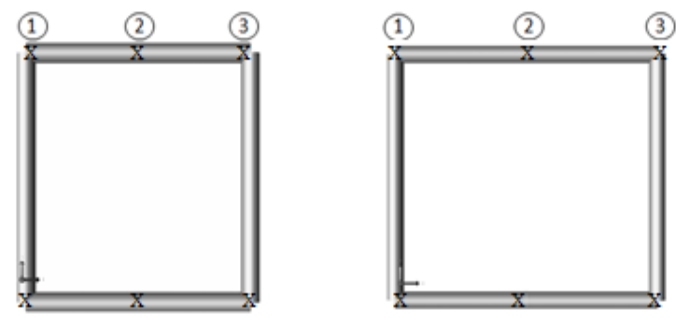

Figure 6. Redesign - horizontal tie-braces of breasting dolphin structure at $\mathrm{El}(+) 0.0$ meter (left) and $\mathrm{El}$ (-) 6 meter (right)

\subsection{Selection Initial Dimension of Tie-Braces}

Selection initial dimension of tie-braces is based on a tubular design parameters in API RP 2A WSD. The tubular design parameter are slenderness ratio $k L / r, D / t$ ratio, $\beta$ ratio, and $\tau$ ratio [5].

a. Outside Diameter
The outside diameter is determined by slenderness ratio calculation.

- Horizontal Tie-Braces

The longest tie-braces is used in the slenderness ratio calculation. It is horizontal tie-braces at El. (+) $0.0 \mathrm{~m}$ (length of tie-braces is $940 \mathrm{~cm}$ ), as seen in Fig. 7.

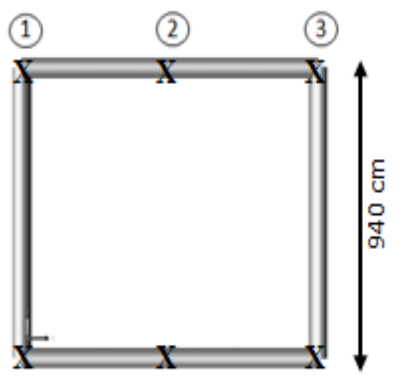

Figure 7. Horizontal tie-braces at el (+) 0.0 meter

1) $k L / r=90$

$$
k L / r=k L / 0.35 D=90
$$$$
D=20.89 \mathrm{~cm}
$$

2) $k L / r=60$

$k L / r=k L / 0.35 D$

$$
D=31.33 \mathrm{~cm}
$$

where:

$k=$ effective length coefficient (horizontal braces) $=0.7$

$L=$ horizontal brace length

$r=$ radius of gyration $=0.35 \mathrm{D}$

$D=$ outside diameter

- Diagonal Tie-Braces

The longest tie-braces is used to slenderness ratio calculation. It is diagonal tie-braces at el (+) $4.65 \mathrm{~m}$ to el $(+) 0.0 \mathrm{~m}$ (length of tie-braces is $945 \mathrm{~cm}$ ).

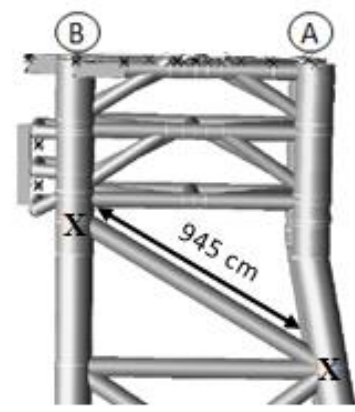

Figure 8. The longest diagonal tie-braces at el (+) 4.65 meter to el $(+) 0.0$ meter

1) $k L / r=90$

$k L / r=k L / 0.35 D=90$

$D=24 \mathrm{~cm}$

2) $k L / r=60$

$k L / r=\mathrm{kL} / 0.35 D$ 


$$
D=36 \mathrm{~cm}
$$

Then, $\beta$ ratio is determined as function of the brace and chord outside diameters, $d$ and $D$, as follows:

$$
\beta=d / D
$$

where:

$\mathrm{d}=$ outside diameter of brace

$\mathrm{D}=$ outside diameter of cord (pile $=115.57 \mathrm{~cm}$ )

The $\beta$ value ranges from $0.2 \sim 0.8$, therefore the outside diameter of tie-braces may be determined:

for $\beta=0.2 \rightarrow d=23.114 \mathrm{~cm}$

for $\beta=0.8 \rightarrow d=92.456 \mathrm{~cm}$

From the calculation of tubular design parameters of slenderness and $\beta$ ratio, the size of the outside diameter of the brace is taken between $23 \mathrm{~cm}$ to $36 \mathrm{~cm}$.

\section{b. Wall Thickness}

The wall thickness of the tubular member is determined by $\tau$ ratio, which is:

$$
\tau=t / T
$$

where:

$t=$ wall thickness of brace

$T=$ wall thickness of cord (pile $=3.165 \mathrm{~cm}$ )

The $\tau$ value ranges from $0.3 \sim 0.7$, therefore the wall thickness of the brace may be found:

$$
\text { for } \tau=0.3 \rightarrow t=0.95 \mathrm{~cm}
$$$$
\text { for } \tau=0.7 \rightarrow t=2.22 \mathrm{~cm}
$$

From the size of the outside diameter and wall thickness of the brace which have been calculated as above, and the consideration of $d / t<60$, the following dimensions of brace is then selected. For $d=36 \mathrm{~cm}$ and $t=0.95 \mathrm{~cm}$, the $d / t=$ 37.89. This means that all braces dimension that had been selected meet the design parameters of:

$24 \mathrm{~cm} \leq d \leq 36 \mathrm{~cm}$

$0.95 \mathrm{~cm} \leq t \leq 2.22 \mathrm{~cm}$

\subsection{Modeling and In-place Analysis}

Breasting dolphin structure modeling was performed using FEM software. The tie-braces outside diameter selected should be selected from those available in the market [6], these are $27.31 \mathrm{~cm}, 32.39 \mathrm{~cm}$, and $35.56 \mathrm{~cm}$. Each outside diameter will be combined with the selected wall thickness that varies randomly, namely $0.95 \mathrm{~cm}, 1.45 \mathrm{~cm}, 1.95 \mathrm{~cm}$, and $2.22 \mathrm{~cm}$ for each structure.

Then in-place analysis will then be done to determine maximum joint deflection check, maximum member stress check (UC), joint punching shear stress check (UC), and total self weight of the structure $[7,8]$.

\subsection{Selection of Optimum Tie-Braces Dimension}

The optimum dimensions of tie-braces are determined with the aid of the graphs plotted on the basis of output data from the in-place analysis on several structures, as presented in Tables $4-6$. The optimum criteria can achieved when the dimensions of the tie-braces intersect with the constraint, also by looking at the minimum self weight of the structure.

Table 4. Results of the in-place analysis for several breasting dolphin structures with $d=27.31 \mathrm{~cm}$

\begin{tabular}{|c|c|c|c|c|}
\hline $\begin{array}{c}\boldsymbol{t} \\
(\mathbf{c m})\end{array}$ & $\begin{array}{c}\text { Deflection } \\
(\mathbf{c m})\end{array}$ & $\begin{array}{c}\text { Member } \\
\text { Stress UC }\end{array}$ & $\begin{array}{c}\text { Joint Punching } \\
\text { Shear UC }\end{array}$ & $\begin{array}{c}\text { Self Weight } \\
\text { (ton) }\end{array}$ \\
\hline 0.95 & 7.06 & 0.96 & 2.28 & 248.56 \\
\hline 1.45 & 6.72 & 0.72 & 1.62 & 254.34 \\
\hline 1.95 & 6.54 & 0.59 & 1.28 & 259.88 \\
\hline 2.22 & 6.48 & 0.54 & 1.15 & 262.77 \\
\hline
\end{tabular}

Table 5. Results of the in-place analysis for several breasting dolphin structures with $d=32.39 \mathrm{~cm}$

\begin{tabular}{|c|c|c|c|c|}
\hline $\begin{array}{c}t \\
(\mathbf{c m})\end{array}$ & $\begin{array}{c}\text { Deflection } \\
(\mathbf{c m})\end{array}$ & $\begin{array}{c}\text { Member } \\
\text { Stress UC }\end{array}$ & $\begin{array}{c}\text { Joint Punching } \\
\text { Shear UC }\end{array}$ & $\begin{array}{c}\text { Self Weight } \\
\text { (ton) }\end{array}$ \\
\hline 0.95 & 6.97 & 0.82 & 2.01 & 247.35 \\
\hline 1.45 & 6.67 & 0.62 & 1.38 & 254.30 \\
\hline 1.95 & 6.52 & 0.51 & 1.08 & 261.02 \\
\hline 2.22 & 6.46 & 0.47 & 0.97 & 264.55 \\
\hline
\end{tabular}

Table 6. Results of the in-place analysis for several breasting dolphin structures with $d=35.56 \mathrm{~cm}$

\begin{tabular}{|c|c|c|c|c|}
\hline $\begin{array}{c}\boldsymbol{t} \\
(\mathbf{c m})\end{array}$ & $\begin{array}{c}\text { Deflection } \\
(\mathbf{c m})\end{array}$ & $\begin{array}{c}\text { Member } \\
\text { Stress UC }\end{array}$ & $\begin{array}{c}\text { Joint Punching } \\
\text { Shear UC }\end{array}$ & $\begin{array}{c}\text { Self Weight } \\
\text { (ton) }\end{array}$ \\
\hline 0.95 & 6.94 & 0.76 & 2.00 & 246.25 \\
\hline 1.45 & 6.66 & 0.58 & 1.27 & 253.93 \\
\hline 1.95 & 6.52 & 0.48 & 0.99 & 261.38 \\
\hline 2.22 & 6.46 & 0.44 & 0.88 & 265.31 \\
\hline
\end{tabular}

Taking the data from Tables $4-6$, the graphs of optimization are then established, as shown in Figs. $9-11$.

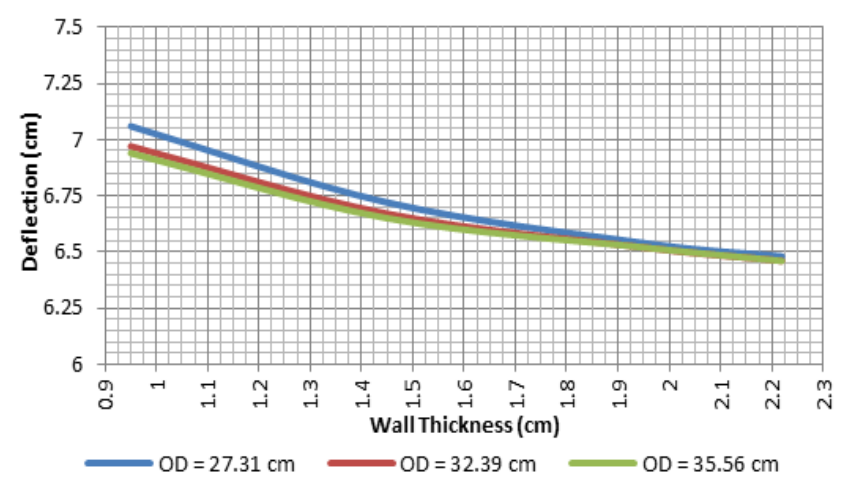

Figure 9. Optimization graph of deflection check

Figure 9 shows that all structures satisfy the deflection check and even had a deflection which is far below the allowable deflection limits. The optimum point is determined by looking at the deflection that intersects with the allowable deflection limits or close to the allowable deflection limit. So the outside diameter is $27.31 \mathrm{~cm}$ and the wall thickness is $0.95 \mathrm{~cm}$. 


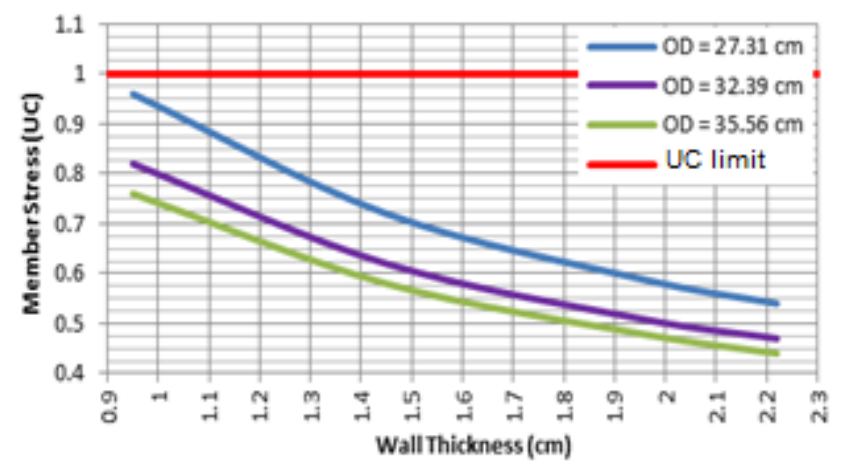

Figure 10. Optimization graph of member stress check

Figure 10 shows that all structures satisfy the members UC stress check, which is below the allowable limit. The optimum point is determined by looking at the members stress that intersects with allowable UC limit or close to the allowable UC limit. So the outside diameter $27.35 \mathrm{~cm}$ and the wall thickness is $0.95 \mathrm{~cm}$.

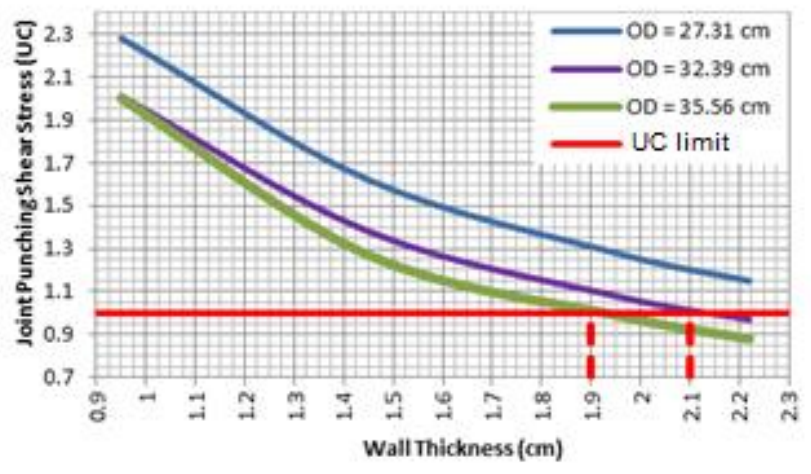

Figure 11. Optimization graph of joint punching shear stress check

From Fig. 11 it can be seen that the intersection point with the allowable UC limits occurs in two variations. The first is for outside diameter $35.56 \mathrm{~cm}$ and wall thickness 1.9 $\mathrm{cm}$, and the second is for those $32.39 \mathrm{~cm}$ and $2.1 \mathrm{~cm}$, respectively.

Because of the results of the deflection check and member stress check are in agreement with all combinations of tie-braces dimension, thus the optimum dimension is primarily determined by the results of the joint punching shear stress check. On the optimization graph of joint punching shear stress check in Fig. 11, there are two points of intersection between the two outside diameters with the constraint (allowable UC limit). This means there are two points that occur as the optimum. Because the scope of this case is the optimization of tie-braces design of existing breasting dolphin structures (installed), then to determine the optimum dimensions is by looking at the minimum weight of the structure from two dimensions that has been selected.
In the two tie-braces dimensions, the selected wall thickness (see Fig. 11) will then be selected in accordance with API 5L with size approaching $1.9 \mathrm{~cm}$ for OD $35.56 \mathrm{~cm}$ and approaching $2.1 \mathrm{~cm}$ for OD $32.39 \mathrm{~cm}$. Finally, the optimization results by looking at the minimum weight of the breasting dolphin structure is shown in Table 7.

Table7. Optimization by breasting dolphin structure self

\begin{tabular}{|c|c|c|c|}
\hline $\begin{array}{c}\text { OD } \\
(\mathbf{c m})\end{array}$ & $\begin{array}{c}\text { WT Graph } \\
(\mathbf{c m})\end{array}$ & $\begin{array}{c}\text { WT API 5L } \\
(\mathbf{c m})\end{array}$ & $\begin{array}{c}\text { Self Weight } \\
(\mathbf{k N})\end{array}$ \\
\hline 32.39 & 2.1 & 2.06 & 2574.77 \\
\hline 35.56 & 1.9 & 1.91 & 2558.38 \\
\hline
\end{tabular}

From Table 7 it can be determined that the most optimum dimensions for the tie-braces of the redesigned breasting dolphin for the Berhala Strait is with the outside diameter of $35.56 \mathrm{~cm}$ and wall thickness $1.91 \mathrm{~cm}$, in view of it has the smallest weight of the structure.

\subsection{Review and Analysis}

Redesign of breasting dolphin structure owned by Petrochina International Jabung Ltd on Terminal Oil/Condensate in the Berhala Strait, offshore Jambi, Indonesia has been done in 2014. It is intended to strengthen the breasting dolphin structure that almost collapse due to the increasing load by export tankers activity. Especially, the increasing load is due to an increase in tankers DWT.

The results of redesign shows that breasting dolphin with additional horizontal tie-braces at El. (+) $4.65 \mathrm{~m}, \mathrm{El}$. (+) $0.00 \mathrm{~m}$, and El. (-) $6.00 \mathrm{~m}$ and the diagonal tie-braces from El. (+) $4.65 \mathrm{~m}$ to (+) $0.00 \mathrm{~m}$, and from El. (+) $0.00 \mathrm{~m}$ to (-) $6.00 \mathrm{~m}$ are managed to made the structure safer and to keep it operating. The mostly used of tie-braces configurations is $\mathrm{X}$-brace type with the outside diameter between $32.39 \mathrm{~cm}$ to $50.8 \mathrm{~cm}$ and wall thickness between $1.27 \mathrm{~cm}$ to $1.91 \mathrm{~cm}$.

From the in-place analysis at operational condition to existing breasting dolphin structure, shows the maximum deflection is $5.32 \mathrm{~cm}$, UC maximum member stress is 0.46 , $\mathrm{UC}$ maximum joint punching shear stress is 1.50 , and the self weight of the structure is 264 ton.

In this optimization analysis of existing breasting dolphin, obtained that optimum configuration for breasting dolphin redesign is $\mathrm{V}$ and $\mathrm{X}$ - brace types with the outside diameter of $35.56 \mathrm{~cm}$ and wall thickness is $1.91 \mathrm{~cm}$.

From the in-place analysis at operational condition to redesign of breasting dolphin structure, shows the maximum deflection is $6.53 \mathrm{~cm}$, UC maximum member stress is 0.48 , UC maximum joint punching shear stress is 1.00 , and the self weight of the structure is 261 ton.

Considering the above, differences in results of the existing and the redesigned breasting dolphin are as summarized in Table 8. 
Table 8. The differences in results of existing and redesigned breasting dolphin

\begin{tabular}{|c|c|c|}
\hline Items & Existing & Redesign \\
\hline Self Weight (ton) & 264 & 261 \\
\hline Maximum Joint Deflection $(\mathrm{cm})$ & 5.32 & 6.53 \\
\hline Maximum Member Stress (UC) & 0.46 & 0.48 \\
\hline Maximum Joint Punching Shear (UC) & 1.50 & 1.00 \\
\hline Outside Diameter of Tie-Braces $(\mathrm{cm})$ & $32.39-50.8$ & 35.56 \\
\hline Wall Thickness of Tie-Braces $(\mathrm{cm})$ & $1.27-1.91$ & 1.91 \\
\hline Number of Tie-Braces (unit) & 46 & 28 \\
\hline
\end{tabular}

\section{CONCLUSIONS}

Based on the results of modeling and further the analyses, the current study concludes:

- Optimum tie-braces dimension for strengthened breasting dolphin at Petrochina Marine Terminal is $35.56 \mathrm{~cm}$ for the outside diameter and $1.91 \mathrm{~cm}$ for the wall thickness, with configuration of the $\mathrm{V}$ and $\mathrm{X}-$ brace types.

- The optimum self weight of the structure is 261 ton with the maximum deflection of $6.53 \mathrm{~cm}$, UC maximum member stress of 0.48 and UC maximum joint punching shear stress of 1.00 .

\section{ACKNOWLEDGEMENTS}

The authors are deeply indebted to all people that give a lot of support in finishing the project. Without the supports from PT. ZEE Indonesia this work might not be successfully carried out.

\section{REFERENCES}

1. T026-ZR-2001: In-place analysis for dolphin platform. Project Report, PT Encona Ini Industri. Jakarta, 2014

2. Triatmodjo, B.: Port Design. Beta Offset. Yogyakarta, 2009 (in Indonesian)

3. Rosyid, D.M.: Optimization: Quantitative Approach in Decision Making Technique. Department of Ocean Engineering, ITS, Surabaya, 2009 (in Indonesian)

4. Chakrabarti, S.K.: Handbook of Offshore Engineering. Elsevier, Oxford, 2005

5. API: Recommended Practice for Planning, Designing and Constructing Fixed Offshore Platform-Working Stress Design, API Recommended Practice 2A (API RP2A WSD). American Petroleum Institute, Washington, DC, 2010

6. API: Specification for Line Pipe (API 5L). American Petroleum Institute, Washington, DC, 2004

7. Nuriman, F., Handayanu, and Prastianto, R.W.: Pushover analysis on deck extension of HZEB wellhead tripod jacket platform due to extreme environmental load. National Seminar on Theory and Applied Marine Technology (SENTA 2012), Surabaya, Indonesia (in Indonesian)

8. Anggoronadhi, D., Prastianto, R.W., and Handayanu: Stress analysis on skirt pile due to operational and extreme loads. National Seminar on Theory and Applied Marine Technology (SENTA 2012), Surabaya, Indonesia (in Indonesian) 